\title{
Financial Homo Ignorans: measuring vulnerability to behavioral biases in household finance
}

\author{
Kinga Barrafremª, Daniel Västfjäll ${ }^{\mathrm{b}}$, Gustav Tinghög ${ }^{\mathrm{c}}$ \\ Revised version: 01.12.2020
}

\begin{abstract}
Understanding systematic differences in sound financial behavior between individuals is a key area for public policy and provides the possibility to tailor interventions to promote financial well-being. In this paper we develop and validate a concise 12 item questionnaire measuring individual's vulnerability to behavioral biases in household finance - the Financial Homo Ignorans (FHI) Scale. We conduct two studies with general population (total $\mathrm{N}=2508$ ) and show that the FHI scale predicts behavior in a wide range of financial tasks such as consumer purchases, loan choices, or investment decisions, also when controlling for demographics, financial literacy, and other related constructs. In addition, we show that consumer heterogeneity as assessed by the FHI scale explains the variation in household finance management and financial well-being. The FHI scale can be used by researchers, policy makers, and financial institutions to study the psychological underpinnings of financial behavior and design interventions by targeting individuals who are particularly vulnerable.
\end{abstract}

\footnotetext{
${ }^{a}$ Linköping University, Linköping, Sweden, kinga.barrafrem@liu.se

${ }^{\mathrm{b}}$ Linköping University, Linköping, Sweden; Decision Research, Eugene, OR, USA

${ }^{\mathrm{c}}$ Linköping University, Linköping, Sweden
} 


\section{Introduction}

Do you want to know when you will die? If you are like most people, the answer is "no" (Reisch et al. 2020). Avoiding having that information, if it was available, is an understandable human tendency. But people avoid other, more mundane information that has instrumental utility (e.g., can change their preferences and inform better decisions; Sharot and Sunstein, 2020). For example, 60\% of consumers answer "No" to the question "would you like information about the standard fee for late payment of your credit card bill?" (Reisch et al. 2020, Sunstein 2020). Arguably, the main reason for why people sometimes make poor financial decisions is not that they lack knowledge or adequate information or even that individuals lack computational abilities. The main reason is instead that we are inattentive to information, knowledge, and our limited computational abilities. We willfully ignore information freely available to us, we actively avoid information that may be unpleasant, and we sometimes simply neglect to pay attention to information that is relevant to our decisions. This type of ignorance is all around. People are less likely to check on to their stock on days when the market has gone down (Karlsson et al. 2009, Gigerenzer and Garcia-Retamero 2017). One of the authors of this paper never reads his course evaluations and another avoids going to the doctor. Thus, we often choose not to know, even if the potential benefits from knowledge are large and the cost associated with acquiring information is negligible. People can often be described as Homo Ignorans ("neglecting man"; Hertwig and Engel, 2016). This form of willful ignorance is at odds with the traditional Homo Economicus ("economic man") view of decision making, where individuals always should prefer more information to less in order to be able to make decisions that maximize their utility (Blackwell 1953). The overarching research aim of this paper is to further our understanding of why certain individuals are more or less vulnerable to behavioral financial biases driven by ignorance.

A cornerstone in the policies of institutions and organizations is that if relevant information is available, people will use this to their best capability to make an informed decision. However, simply providing information is not enough as peoples' information processing is limited (Simon 1955) and to deal with these limitations people rely on heuristic thinking that may lead to systematic biases. Thus, decision makers are far from Homo Economicus with unlimited cognitive capacity and unlimited computational capacity. Homo Economicus does not under- or overweigh information but is perfectly calibrated in the trade-off thinking. Homo Ignorans, in contrast, actively avoids or passively does not attend to information, even when that information is relevant to the decision (Hertwig and Engel 2016, Golman et al. 2017). Homo Economicus and Homo Ignorans can thus be used as labels to describe two different individual traits when it comes to acquiring and assessing information. On the one hand, Homo Economicus will always attend to relevant and available information. Homo Ignorans, on the other hand, will systematically avoid information, even if it is freely available, and sometimes even be willing to incur a cost to not receive information (Ganguly and Tasoff 2017, Ho et al. 2020). While Homo Ignorans and Homo Economicus can be seen as two endpoints of an information processing continuum, 
people in everyday life probably vary to the degree that they ignore information. Moreover, these individual differences likely produce systematic effects on financial decision-making.

In this study we examine how individual differences in ignorance impact household finance. Building on previous work (Karlsson et al. 2009, C. Strömbäck et al. 2017, Skagerlund et al. 2018, Lind et al. 2020, Camilla Strömbäck et al. 2020), we hypothesize that the ignorance is amplified in the financial decision context due to the high complexity of decisions, the uncertainty of outcomes, and the lack of instant benefits. In this paper we develop a measure to assess systematic individual difference related to behavioral inattention. Secondly, we aim to examine how well this individual difference measure (FHI scale) explains behavior in experimental behavioral finance tasks. Finally, we will also examine if the FHI scale can explain real life financial behaviors.

\section{The FHI scale}

\section{Scale development}

In the construction process we have followed the guidelines on scale development suggested by Carpenter (2018) as well as Worthington and Whittaker (2006). Initially, we identified six primary behavioral biases linked to behavioral inattention: avoiding making a decision (decision avoidance; Anderson, 2003), avoiding available, relevant, information (information avoidance; Golman et al. 2017; Sweeny et al. 2010), inattention to the cumulative value of multiple outcomes (aggregation neglect; Sunstein, 2006), ignorance of the alternative use of money (opportunity cost neglect; Frederick et al. 2009), inattention to belief-inconsistent information (motivated reasoning; Lind et al. 2018; Minson et al. 2019) and inattention to factual information, one's capabilities, and inflated probability judgments of future positive outcomes (over-optimism; Weinstein, 1980). Based on these behavioral biases, we initially created a pool of self-report items. All items were constructed by the authors, except for the items concerning information avoidance that were adapted from Howell and Shepperd (2016) and two of the items concerning opportunity cost that were adapted from Spiller (2011). The first version of the scale consisted of six to eight items for each of the behavioral biases (See Appendix for the full list of initial items).

To measure individual differences in decision avoidance, we used statements that try to identify behaviors regarding postponing, delegating, or avoiding decisions about their current but also future financial situation (De Bondt and Thaler 1995, Dhar 1997, Luce 1998). In addition, we tried to capture different motives for decision avoidance: regret avoidance, emotion-regulation, avoidance of cognitive effort, or inaction inertia (Luce 1998, Anderson 2003, Broniarczyk and Griffin 2014). To measure information avoidance, we have used items adapted from Howell and Shepperd (2016) and modified to fit the financial domain. These items relate to private finance in general, but also everyday expenses and debts. To measure aggregation neglect we have mainly used items that try to capture individuals 
who tend to make multiple small purchases or have their bills paid automatically which makes the expenses less salient, more difficult to keep track of, or register in mental accounts (Heath and Soll 1996, Richard H. Thaler 1999). To measure opportunity cost neglect, we asked participants to report if they consider opportunity cost when making purchases, choosing to borrow money, or to save money (Spiller 2011). Motivated reasoning used statements that try to capture individual differences in people's propensity to think that their financial decisions are superior, and who are not interested in learning or discussing the other ways to manage finance. Finally, to measure overconfidence we used statements that tried to capture individuals who frequently are too optimistic about their financialmanagement decisions and skills, as well as about achieving financial goals.

The pool of 43 items was included in an online survey administered to 506 respondents from the general population in Sweden (Study 1, see descriptive statistics in Table S2 in the Appendix). ${ }^{1}$ The order of items was randomized within each subscale and subscales were randomized. In addition to the initial pool of FHI items, we collected responses to a number of individual difference scales related to financial decision making. Respondents completed the short-term future orientation scale (Antonides et al. 2011) which we adapted to financial-decision context, the mental budgeting scale (Antonides et al. 2011), the scale of propensity to plan (Lynch Jr et al. 2010), the financial self-efficacy scale (Lown 2011), and the "big five" financial literacy scale (Lusardi and Mitchell 2008, Lusardi 2011).

\section{Item reduction and refinement of the scale}

We used both criterions concerning content validity as well exploratory factor analysis (EFA) to narrow down the number of items based on the initial sample. ${ }^{2}$ To represent the six behavioral biases underpinning the FHI scale, but still reduce the total number of items, we decided that three items per bias would be adequate. Thus, based on item intercorrelations, factor dimensions, and content validity 18 items were selected (Table 1).

\footnotetext{
${ }^{1}$ Our target sample size (500) was selected beforehand to be sufficiently large to make reliable inferences in the exploratory factor analysis. A frequent recommendation of the sample size is at least 300 subjects when developing a scale. Comrey and Lee (2013) consider the sample size of 500 as "very good". The analyzed dataset consists of subjects who are above 18 and passed an attention check to minimize careless responding. ${ }^{2}$ We aimed to develop a scale that is extensive enough to capture the underlying concepts but is short enough that can be easily used by many researchers as an additional tool to measure individual differences in financial decision making. This led us to the choice of three items per subscale.
} 
Table 1 Retained items in the FHI scale after Study $1 .^{3}$

\begin{tabular}{|c|c|}
\hline Behavioral bias & Item \\
\hline $\begin{array}{l}\text { decision } \\
\text { avoidance }\end{array}$ & $\begin{array}{l}\text { 1. I postpone making decisions about my future financial situation. } \\
\text { 2. I avoid making decisions about my current financial situation. } \\
\text { 3. Making financial decisions is time-consuming and effortful so I often do not take } \\
\text { active decisions. }\end{array}$ \\
\hline $\begin{array}{l}\text { information } \\
\text { avoidance }\end{array}$ & $\begin{array}{l}\text { 4. I would rather not know how much I spent last month. } \\
\text { 5. I would rather not know the status of my debts. } \\
\text { 6. When it comes to managing my own finances, ignorance is bliss. }\end{array}$ \\
\hline $\begin{array}{l}\text { aggregation } \\
\text { neglect }\end{array}$ & $\begin{array}{l}\text { 7. When I make bigger purchases (e.g., home electronics, TV, holiday travel, etc.) I } \\
\text { choose to pay in installments. } \\
\text { 8. I am often surprised how much money I have spent. } \\
\text { 9. When something costs less than I expected, I often spend what I got over on something } \\
\text { unplanned. }\end{array}$ \\
\hline $\begin{array}{l}\text { opportunity cost } \\
\text { neglect }\end{array}$ & $\begin{array}{l}\text { 10. I often think about the fact that spending money on one purchase now means not } \\
\text { spending money on some other purchase later. } \\
\text { 11. I often consider other specific items that I would not be able to buy if I made a } \\
\text { particular purchase. } \\
\text { 12. When shopping I compare the prices of products with similar use. }\end{array}$ \\
\hline $\begin{array}{l}\text { motivated } \\
\text { reasoning }\end{array}$ & $\begin{array}{l}\text { 13. I think that people who disagree with my opinion how to manage money are foolish. } \\
\text { 14. I unfollow people on social media who do not share my views about spending money. } \\
\text { 15. I dislike people who do not share my views about financial issues. }\end{array}$ \\
\hline overoptimism & $\begin{array}{l}\text { 16. I have unrealistic expectations about my future financial situation. } \\
\text { 17. I rarely achieve my savings goals. } \\
\text { 18. The financial consequences of my decisions usually turn out worse than I expect. }\end{array}$ \\
\hline
\end{tabular}

Next, we conducted another online survey of 2002 respondents of the general population in Sweden (Study 2, see descriptive statistics in Table S2 in the Appendix) in which we presented participants with the 18-item FHI scale. Again, the order of items was randomized. In this final stage of the scale development an exploratory factor analysis with oblique factor rotation was conducted and Bartlett's test of sphericity as well as the Kaiser-Meyer-Olkin (KMO) measure of sampling adequacy was used to verify the factorability of data. Conducting factor analysis was justified (Chi-square test, $p<0.001$; all KMOs $>0.6$ ). At this stage, we decided to remove items measuring overoptimism from the FHI scale, as these items loaded on the same factor as items measuring aggregation neglect. In addition, we have excluded the items dealing with opportunity cost neglect as these items showed a negative correlation with other items. The final version of the scale consists of 12 items and is presented in Table 2 . The Cronbach's alpha of the FHI scale is 0.81 pointing to high reliability of the scale. We have constructed an index variable of these items by taking the average of all 12 items in the scale, i.e., it can take values from 1 (low level of financial ignorance) to 5 (high level of financial ignorance). The distribution of FHI in Study 2 is presented on Figure 1.

\footnotetext{
${ }^{3}$ The aggregation neglect subscale includes items that did not appear in the initial pool of items. As the subscale was not performing satisfactorily, we constructed new items and conducted additional data collection for this subscale (connected to another unrelated study, $\mathrm{N}=1008$ ).
} 
Table 2 All items included in the final version of the FHI Scale

\begin{tabular}{|c|c|}
\hline Behavioral bias & Item \\
\hline decision avoidance & $\begin{array}{l}\text { 1. I postpone making decisions about my future financial situation. } \\
\text { 2. I avoid making decisions about my current financial situation. } \\
\text { 3. Making financial decisions is time-consuming and effortful so I often do not } \\
\text { take active decisions. }\end{array}$ \\
\hline information avoidance & $\begin{array}{l}\text { 4. I would rather not know how much I spent last month. } \\
\text { 5. I would rather not know the status of my debts. } \\
\text { 6. When it comes to managing my own finances, ignorance is bliss. }\end{array}$ \\
\hline aggregation neglect & $\begin{array}{l}\text { 7. When I make bigger purchases (e.g., home electronics, TV, holiday travel, etc.) } \\
\text { I choose to pay in installments. } \\
\text { 8. I am often surprised how much money I have spent. } \\
\text { 9. When something costs less than I expected, I often spend what I got over on } \\
\text { something unplanned. }\end{array}$ \\
\hline motivated reasoning & $\begin{array}{l}\text { 10. I think that people who disagree with my opinion how to manage money are } \\
\text { foolish. } \\
\text { 11. I unfollow people on social media who do not share my views about spending } \\
\text { money. } \\
\text { 12. I dislike people who do not share my views about financial issues. }\end{array}$ \\
\hline
\end{tabular}

Figure 1 Distribution of the FHI index

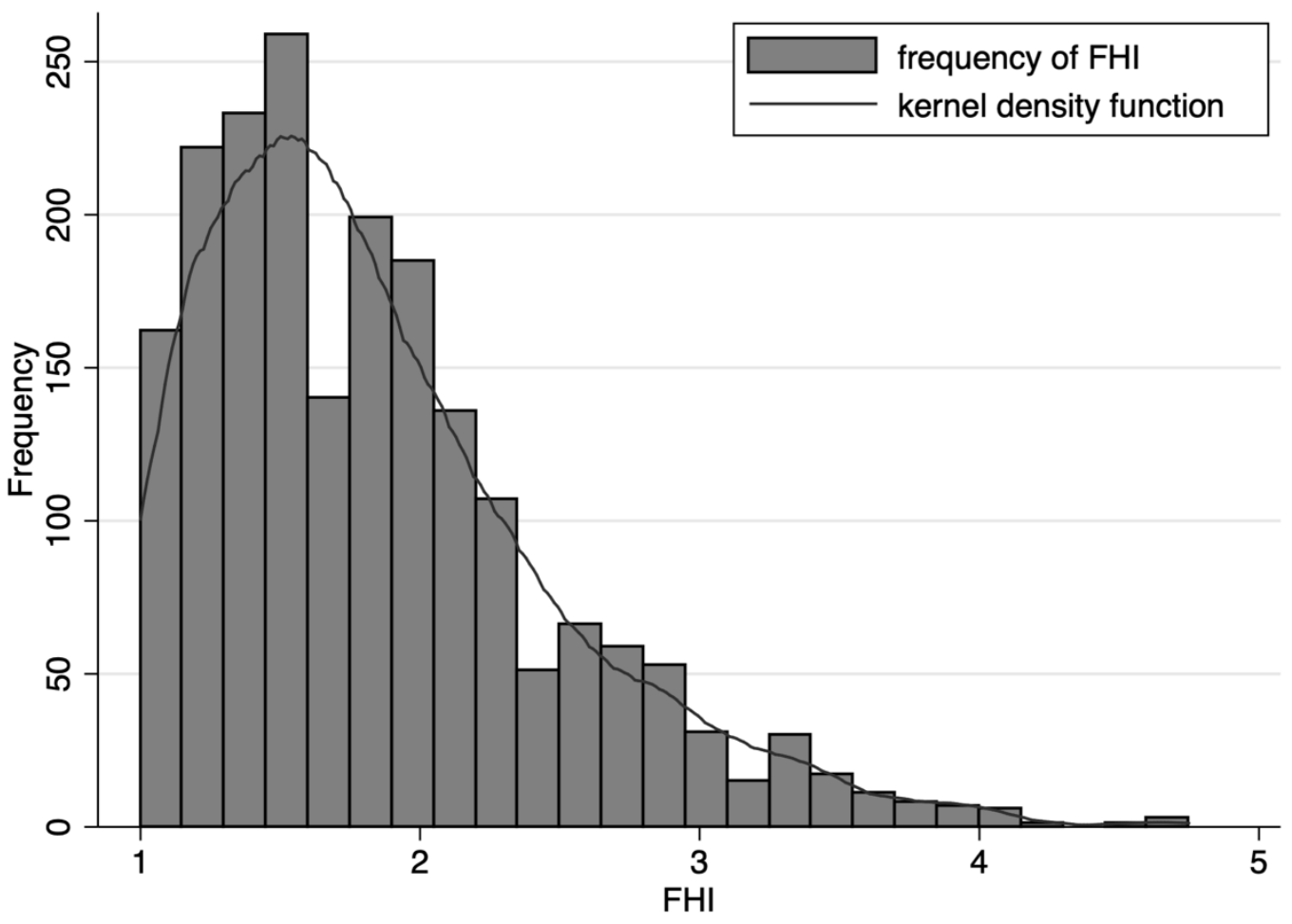

\section{Convergent and discriminatory validity of the FHI scale}

In the initial data collection, we included previously validated individual difference scales to establish convergent and discriminant validity. We predict that the FHI scale will be related to the financial selfefficacy scale. According to Bandura (2010), individuals with low self-efficacy do not have sufficient confidence in own abilities to complete a task (here: make financial decisions) and thus are more likely to avoid it and less likely to preserve when facing difficulties. Similarly, Sweeny et al. (2010) suggest that individuals with low-self efficacy are more likely to avoid acquiring information as they may feel like they do not have capabilities to use it. In addition, we expect that the FHI scale will correlate with 
the short-term future orientation scale. Short-term future orientation scale identifies individuals who focus on convenience and present situation, who ignore difficulties and the potential future consequences of their decisions. In turn, we expect that our scale will not be related to the mental budgeting scale, as this scale focuses on how people compartmentalize their incomes, wealth and expenses. While it is possible that individuals ignore some outcomes when budgeting, the mental budgeting scale mainly identifies whether individuals violate the assumption of money fungibility. Furthermore, we expect weak correlation between the FHI scale and the scale of propensity to plan. Individuals might make plans about their financial budgets, however, still ignore specific decision factors in these plans. In addition, we argue that the FHI scale and the financial literacy scale measure similar but different concepts. Individuals, who score high on financial literacy, are usually those who do not ignore information, but rather acquire it, try to understand it, and use it in the decision-making to their benefits. However, while financial literacy focuses mainly on the factual knowledge of individuals, the FHI scale focuses on the behavioral aspects of acquiring and using the knowledge. Table 3 shows pairwise correlations between the FHI scale and the above-mentioned scales. As expected, only the correlations between the FHI scale and financial self-efficacy as well as the shortterm future orientation are considered strong (Pearson's $r>0.4$ ). The correlations between the FHI scale and the mental budgeting scale and the propensity to plan scale are weak and not statistically significant. The correlation between the FHI scale and financial literacy scale is weak-to-moderate and statistically significant.

Table 3 Pairwise correlations between the FHI scale and selected established scales $(n=506)$.

\begin{tabular}{l|lllll} 
Scale & Self-efficacy & $\begin{array}{l}\text { Short-term future } \\
\text { orientation }\end{array}$ & $\begin{array}{l}\text { Mental } \\
\text { budgeting }\end{array}$ & $\begin{array}{l}\text { Propensity to } \\
\text { plan }\end{array}$ & $\begin{array}{l}\text { Financial } \\
\text { literacy }\end{array}$ \\
\hline \hline Pearson's $\mathrm{r}$ & $0.566 * * *$ & $0.469 * * *$ & -0.018 & -0.067 & $-0.240 * * *$ \\
Note: $* \mathrm{p}<.05, * * \mathrm{p}<.01, * * * \mathrm{p}<.001$. Self-efficacy takes values between 1 (high financial self-efficacy) and 4 (low financia
\end{tabular}
self-efficacy). Short-term future orientation takes values between 1 (low focus on short term) and 5 (high focus on short term). Mental budgeting takes values between 1 (low mental budgeting) and 5 (high mental budgeting). Propensity to plan takes values between 1 (low propensity to plan) and 6 (high propensity to plan). Financial literacy takes values between 0 (low financial literacy) and 5 (high financial literacy). Since these scales were collected in Study 1, the items on the aggregation neglect subscale in the FHI scale are slightly different than in the final version of the scale.

In sum, the Financial Homo Ignorans scale has, thus far, been shown to have good reliability, to assess construct that is related to but distinguishable from self-efficacy, short-term future orientation, and financial literacy, and to be unrelated to mental budgeting and propensity to plan.

\section{Can FHI explain performance in behavioral finance tasks?}

Next, we investigate whether the FHI scale can capture individual differences in financial outcomes. In the same survey as the final version of the FHI scale was administered, participants conducted a series of short experimental behavioral finance tasks (English translation of the instructions to all tasks are presented in Appendix). 
Task 1. Pension investment and decision avoidance. To measure decision avoidance in financial decisions, we have asked subjects to decide how they want to invest their funds collected in their Premium Pension Plan (PPP). ${ }^{4}$ They were presented with a list of top 5 PPP-funds according to a wellknown financial advisory firm for private and business consumers that has a popular blog providing financial advice (Småspararguiden). For each mutual fund we showed information about the managing fees, the proportion of stocks in the mutual fund, whether the proportion of safe investments (bonds) increases as the investor's retirement age approaches, their index of ethical investment, as well as the region of markets in which the money is invested on. To minimize the problem of differences in financial knowledge, subjects were also provided with clarification of these terms. Individuals could choose one of the five mutual funds, decide to stick with status quo, or delegate the decision to someone else. The last two answers were classified as decision avoidance. We will refer to this task as Pension Investment.

Task 2. Mutual fund investment and information avoidance. We presented subjects with a scenario in which they planned to start monthly savings in a Swedish mutual fund. Subjects were shown a table with four existing Swedish funds on the market, the managing fee, their last year's rate of return, their index of ethical investment, the number of firm stocks that the mutual fund consists of, and risk index. To minimize the problem of differences in financial knowledge, subjects were also provided with clarification of these terms. Optionally, subjects could with one mouse click choose to show more information about each mutual fund including the five-year rate of return and the Morningstar Rating. ${ }^{5}$ Individuals could then choose one of the four mutual funds, postpone the decision until later, or delegate the decision to someone else. We define information ignorance as a situation in which an individual did not reveal the additional information. Furthermore, we use the answer to this task in the analysis of decision avoidance, in which postponing and delegating decision is classified as decision avoidance. We will refer to this task as Mutual Fund Investment.

Task 3. Loan choice and aggregation neglect. Based on Lunn et al. (2016), we used a paradigm where every participant was presented with two decision scenarios in which they wanted to borrow money from the bank for a car purchase or an apartment renovation. Individuals could choose from two loans: one that was slightly shorter with higher interest rate (higher monthly repayment but lower total cost) and one that was longer with lower interest rate (lower monthly repayment but higher total cost). Additionally, individuals were shown the monthly repayment for each of the loans in one randomly

\footnotetext{
${ }^{4} \mathrm{PPP}$ is a defined contribution component of the Swedish social security system. It is based on fully funded individual accounts that individual members are in charge of. Individuals can select up to five mutual funds from a predefined set of almost 1000 mutual funds. Those who do not make an active choice have their investments automatically assigned to a default fund.

${ }^{5}$ A measure of a fund's risk-adjusted return, relative to similar funds. It is frequently used by investors as a help in the choice of investments.
} 
chosen scenario and the total cost of a loan in the other scenario. The order of scenarios was randomized. We will refer to this task as Loan Choice.

Task 4. Political statements and motivated reasoning. In this task we asked participants to what extent they agree with six political statements related to financial issues (e.g., about the consequences of raising income tax). Three statements characterized right-wing politics and three statements characterized left-wing politics. The order of statements was randomized. In addition, individuals stated their political orientation and reported which party they would vote for in elections. We will refer to this task as Political Statements.

Task 5. Consumer purchase and opportunity cost neglect. We additionally measured the tendency to make consumer purchases and the sensitivity to opportunity cost using the paradigm developed by Frederick et al. (2009). Individuals were presented with two separate scenarios in which they considered a purchase of a mobile phone or a tv. Both goods were currently on discount. In one randomly chosen scenario individuals were reminded of an opportunity cost of their purchase through the framing of the alternative not to buy the good (i.e., they saw "No. Save the money for other purchases" instead of "No"). The order of scenarios was randomized. We will refer to this task as Consumer Purchase.

To examine the effect of individual differences in FHI on these tasks, separate regressions was run with FHI as a predictor along with control variables

\section{Results}

Pension Investment and decision avoidance. The dependent variable takes value 1 if a person chooses to keep status quo, delegate, or postpone a decision and 0 otherwise. ${ }^{6}$ Table 4 presents the results from linear regression on the choice to avoid the decision. Individuals who score higher on the FHI scale are more likely to avoid the decision. For example, one additional point on the FHI scale is associated with the increase in the likelihood of decision avoidance by 3.2 percentage points (column 1). However, once we control for financial literacy, the relationship between the FHI scale and the decision avoidance becomes insignificant. This may be caused by high relevance of financial literacy in the investment decisions. ${ }^{7}$

\footnotetext{
${ }^{6}$ In the Mutual Fund Investment task, subjects could reveal optional information which could potentially influence their decision avoidance. However, we found that revealing information was unrelated with decision avoidance and thus we pooled the answers in this task together with the answers to Pension Investment task in the analysis. The results are qualitatively similar if we consider the answers to each task separately.

${ }^{7}$ The current default option in Premium Pension Plan in Sweden (AP7 Såfa) has outperformed most of other funds, and thus the decision of sticking with the default Premium Pension Plan is frequently recommended by financial advisors. This suggests that sticking with the default can be motivated by reasons other than decision avoidance and thus our results may be more pronounced for decisions that don't have a clearly good default option.
} 
Table 4 Linear regression explaining the choice to avoid decision about the allocation of Premium Pension Plan or investment in Swedish mutual funds

\begin{tabular}{lcc} 
VARIABLES & $(1)$ & $(2)$ \\
\hline & & \\
FHI & $0.032^{* *}$ & -0.012 \\
Age & $(0.014)$ & $(0.014)$ \\
& 0.000 & $0.001^{* *}$ \\
Female & $(0.001)$ & $(0.001)$ \\
& $0.110^{* * *}$ & $0.050^{* * *}$ \\
Education, Upper-sec. & $(0.016)$ & $(0.016)$ \\
& $-0.081^{* *}$ & -0.032 \\
Education, Post-sec. lower & $(0.036)$ & $(0.034)$ \\
& $-0.125 * * *$ & $-0.061^{*}$ \\
Education, Post-sec. higher & $(0.038)$ & $(0.036)$ \\
& $-0.173 * * *$ & $-0.089 * * *$ \\
Fin. literacy & $(0.035)$ & $(0.034)$ \\
& & $-0.081^{* * *}$ \\
Constant & & $(0.007)$ \\
& $0.230^{* * *}$ & $0.467 * * *$ \\
Observations & $(0.058)$ & $(0.059)$ \\
R-squared & & \\
\hline
\end{tabular}

Note: Standard errors clustered at the subject level in parentheses. ${ }^{* * *} \mathrm{p}<0.01,{ }^{* *} \mathrm{p}<0.05,{ }^{*} \mathrm{p}<0.1$. Dependent variable: avoid the decision (remain with status quo or postpone/delegate the decision). FHI takes values between 1 (low ignorance) and 5 (high ignorance). The reference category for education is lower-secondary. Financial Literacy takes values between 0 (low financial literacy) and 5 (high financial literacy).

Mutual Fund Investment and information avoidance. Table 5 presents the results from linear regression on the choice to reveal the optional information. Individuals who score higher on the FHI scale are less likely to reveal the information. For example, one additional point on the FHI scale is associated with the decrease in the likelihood of revealing information by 5.6 percentage points (column 2). 
Table 5 Linear regression explaining the choice to reveal the optional information

\begin{tabular}{lcc} 
VARIABLES & $(1)$ & $(2)$ \\
\hline & & \\
FHI & $-0.080 * * *$ & $-0.056^{* * *}$ \\
Age & $(0.016)$ & $(0.017)$ \\
Female & $-0.003^{* * *}$ & $-0.004 * * *$ \\
& $(0.001)$ & $(0.001)$ \\
Education, Upper-sec. & -0.014 & 0.020 \\
& $(0.020)$ & $(0.021)$ \\
Education, Post-sec. lower & 0.006 & -0.022 \\
& $(0.037)$ & $(0.037)$ \\
Education, Post-sec. higher & 0.029 & -0.007 \\
& $(0.040)$ & $(0.040)$ \\
Fin. literacy & 0.035 & -0.012 \\
& $(0.037)$ & $(0.038)$ \\
Constant & & $0.046^{* * *}$ \\
& & $(0.008)$ \\
& $0.572 * * *$ & $0.438^{* * *}$ \\
Observations & $(0.066)$ & $(0.070)$ \\
R-squared & & \\
\hline
\end{tabular}

Note: Robust standard errors in parentheses. ${ }^{* * *} \mathrm{p}<0.01,{ }^{*} \mathrm{p}<0.05,{ }^{*} \mathrm{p}<0.1$. Dependent variable: reveal the information. FHI takes values between 1 (low ignorance) and 5 (high ignorance). The reference category for education is lower-secondary. Financial Literacy takes values between 0 (low financial literacy) and 5 (high financial literacy).

Loan Choice and aggregation neglect. Table 6 presents the results from linear regression on the choice of the longer-term loan (i.e., the loan with higher total cost). In the specification we have included a dummy variable that indicated if an individual was shown the total loan cost (Total cost) and an interaction term between total cost condition and the FHI scale. ${ }^{8}$ Individuals who score higher on the FHI scale are more likely to choose the longer-term loan when total cost is not explicitly shown. For example, one additional point on the FHI scale is associated with the increase in the likelihood of choosing the longer-term loan by 6.3 percentage points (column 2). Furthermore, if the total cost of a loan is shown, the effect of financial ignorance is even stronger: one additional point on the FHI scale is associated with the increase in the likelihood of choosing the longer-term loan by 12.3 percentage points $(6.3+6=12.3)$. This means that the FHI scale can both, predict cross-consumer differences in the loan choices but also their susceptibility to the framing of loans. Individuals who score lower on the FHI scale are more likely to be affected by the explicit total cost of a loan. What is more, our results corroborate the findings of Lunn et al. (2016) of the existence of aggregation neglect: showing the total cost of a loan to an individual, increases the weight put on the aggregate costs and thus decreases the likelihood of choosing the longer-term loan.

\footnotetext{
${ }^{8}$ In this analysis we use both decisions for each individual: one in the monthly repayment condition and one in the total cost condition. However, the results are qualitatively similar if we only use the first decision to avoid historical dependence of decisions.
} 
Table 6 Linear regression explaining the choice of the loan with longer term, lower interest rate, and higher total cost.

\begin{tabular}{lcc} 
VARIABLES & $(3)$ & $(4)$ \\
\hline & & \\
Total cost & $-0.475^{* * *}$ & $-0.475^{* * *}$ \\
& $(0.041)$ & $(0.041)$ \\
FHI & $0.083^{* * *}$ & $0.063^{* * *}$ \\
& $(0.018)$ & $(0.018)$ \\
Total cost \# FHI & $0.060^{* * *}$ & $0.060^{* * *}$ \\
& $(0.022)$ & $(0.022)$ \\
Age & $0.001 *$ & $0.001 * * *$ \\
& $(0.000)$ & $(0.000)$ \\
Female & 0.008 & -0.019 \\
& $(0.015)$ & $(0.016)$ \\
Education, Upper-sec. & $-0.081 * * *$ & $-0.058^{* *}$ \\
& $(0.029)$ & $(0.029)$ \\
Education, Post-sec. lower & $-0.078^{* *}$ & -0.049 \\
& $(0.032)$ & $(0.032)$ \\
Education, Post-sec. higher & $-0.113 * * *$ & $-0.074 * *$ \\
& $(0.029)$ & $(0.029)$ \\
Fin. literacy & & $-0.037 * * *$ \\
& & $(0.006)$ \\
Constant & $0.443^{* * *}$ & $0.553^{* * *}$ \\
& $(0.056)$ & $(0.058)$ \\
Observations & & \\
R-squared & 4,004 & 4,004 \\
\hline
\end{tabular}

Note: Standard errors clustered at the subject level in parentheses. ${ }^{* * *} \mathrm{p}<0.01, * * \mathrm{p}<0.05, * \mathrm{p}<0.1$. Dependent variable: choice of the longer-term loan. Total cost takes value 1 when a person was presented the total cost of a loan a 0 otherwise. FHI takes values between 1 (low ignorance) and 5 (high ignorance). The reference category for education is lower-secondary. Financial Literacy takes values between 0 (low financial literacy) and 5 (high financial literacy).

Political Statement and motivated reasoning. Table 7 presents the results from linear regression on the support for each of the statements. In the specification we have included self-reported political orientation, the type of statement (either congruent with right- or left-wing politics, Right-wing statement), and an interaction term between political orientation of a subject and the type of statement. ${ }^{9}$ As can be seen, the FHI scale predicts stronger support for each of the statements when controlling for individual's political orientation and the statement type. For example, one additional point on the FHI scale is associated with the increase in the support of a statement by 0.2 units (on a five-point scale; column 2).

\footnotetext{
${ }^{9}$ In the analysis we use self-reported political orientation as explanatory variable. We also collected information related to the party an individual would vote for, based on which we created an alternative variable measuring political orientation. The results are qualitatively similar if we use this alternative variable to control for participant's political orientation.
} 
Table 7 Linear regression explaining the support for political statements related to financial matters.

\begin{tabular}{lcc} 
VARIABLES & $(1)$ & $(2)$ \\
\hline Right-wing statement & $-2.652^{* * *}$ & $-2.652^{* * *}$ \\
Political orientation & $(0.101)$ & $(0.101)$ \\
& $-0.356^{* * *}$ & $-0.356^{* * *}$ \\
Right-wing statement $\#$ & $(0.013)$ & $(0.013)$ \\
Political orientation & $0.628^{* * *}$ & $0.628^{* * *}$ \\
FHI & $(0.021)$ & $(0.021)$ \\
& $0.213^{* * *}$ & $0.204^{* * *}$ \\
Age & $(0.020)$ & $(0.020)$ \\
& -0.001 & -0.001 \\
Female & $(0.001)$ & $(0.001)$ \\
& 0.005 & -0.007 \\
Education, Upper-sec. & $(0.022)$ & $(0.023)$ \\
& 0.008 & 0.018 \\
Education, Post-sec. lower & $(0.049)$ & $(0.049)$ \\
& -0.029 & -0.016 \\
Education, Post-sec. higher & $(0.051)$ & $(0.051)$ \\
& -0.010 & 0.007 \\
Fin. literacy & $(0.048)$ & $(0.049)$ \\
& & $-0.016^{*}$ \\
Constant & & $(0.009)$ \\
& $3.891 * * *$ & $3.940 * * *$ \\
Observations & $(0.098)$ & $(0.103)$ \\
R-squared & & 12,012 \\
\hline
\end{tabular}

Note: Standard errors clustered at the subject level in parentheses. ${ }^{* *} \mathrm{p}<0.01,{ }^{* *} \mathrm{p}<0.05,{ }^{*} \mathrm{p}<0.1$. Dependent variable: support for the statement. Right-wing statement is a binary variable that takes value 1 if statement is congruent with right-wing politics and zero otherwise. Political orientation is a variable that takes values between 1 (extreme left) and 8 (extreme right). FHI takes values between 1 (low ignorance) and 5 (high ignorance). The reference category for education is lower-secondary. Financial Literacy takes values between 0 (low financial literacy) and 5 (high financial literacy).

Consumer Purchase and opportunity cost neglect. Table 8 shows the results from a linear regression on the decision to buy a product (a mobile phone or a tv). We have introduced a binary treatment variable that takes value 1 if an individual was reminded of the opportunity cost and 0 otherwise (Opportunity cost), as well as an interaction between the opportunity cost reminder and FHI scale as additional covariates. As can be seen, individuals scoring higher on the FHI scale are more likely to make a purchase. For example, one additional point on the FHI scale is associated with the increase in the likelihood of a purchase by 5.9 percentage points (column 2). Furthermore, the interaction effect between opportunity cost and FHI scale is not statistically significant, suggesting no evidence that the effect of financial ignorance on consumer purchases varies with opportunity cost reminder. Lastly, we cannot corroborate the results from Frederick et al. (2009) that opportunity cost reminder decreases the likelihood of a purchase. 
Table 8 Linear regression explaining the likelihood of purchasing a product (a mobile phone or a tv).

\begin{tabular}{|c|c|c|}
\hline VARIABLES & $(1)$ & $(2)$ \\
\hline \multirow[t]{2}{*}{ FHI } & $0.042 * *$ & $0.059 * * *$ \\
\hline & $(0.018)$ & $(0.019)$ \\
\hline \multirow[t]{2}{*}{ Opportunity cost } & -0.009 & -0.009 \\
\hline & $(0.035)$ & $(0.035)$ \\
\hline \multirow[t]{2}{*}{ Opportunity cost \# FHI } & 0.001 & 0.001 \\
\hline & $(0.018)$ & $(0.018)$ \\
\hline \multirow[t]{2}{*}{ Age } & $-0.002 * * *$ & $-0.002 * * *$ \\
\hline & $(0.001)$ & $(0.001)$ \\
\hline \multirow[t]{2}{*}{ Female } & $-0.049 * * *$ & -0.026 \\
\hline & $(0.018)$ & $(0.019)$ \\
\hline \multirow[t]{2}{*}{ Education, Upper-sec. } & $0.080 * *$ & $0.060 *$ \\
\hline & $(0.035)$ & $(0.034)$ \\
\hline \multirow[t]{2}{*}{ Education, Post-sec. lower } & $0.086 * *$ & 0.061 \\
\hline & $(0.037)$ & $(0.037)$ \\
\hline \multirow[t]{2}{*}{ Education, Post-sec. higher } & $0.097 * * *$ & $0.064 *$ \\
\hline & $(0.034)$ & $(0.035)$ \\
\hline \multirow[t]{2}{*}{ Fin. literacy } & & $0.032 * * *$ \\
\hline & & $(0.007)$ \\
\hline \multirow[t]{2}{*}{ Constant } & $0.387 * * *$ & $0.294 * * *$ \\
\hline & $(0.063)$ & $(0.066)$ \\
\hline Observations & 4,004 & 4,004 \\
\hline R-squared & 0.015 & 0.021 \\
\hline \multicolumn{3}{|c|}{$\begin{array}{l}\text { Note: Standard errors clustered at the subject level in parentheses. } * * * \mathrm{p}<0.01, * * \mathrm{p}<0.05, * \mathrm{p}<0.1 \text {. Dependent } \\
\text { variable: purchase of a product (tv or mobile phone). FHI takes values between } 1 \text { (low ignorance) and } 5 \text { (high } \\
\text { ignorance). Opportunity cost takes values } 1 \text { if a person was reminded about opportunity cost or } 0 \text { otherwise. The } \\
\text { reference category for education is lower-secondary. Financial Literacy takes values between } 0 \text { (low financial } \\
\text { literacy) and } 5 \text { (high financial literacy). }\end{array}$} \\
\hline
\end{tabular}

Thus far, we have shown that the FHI scale, can predict behavior in a number of experimental behavioral finance tasks. In the next step, we are interested if the FHI scale can capture differences in broader, real-life financial outcomes related to financial health, such as financial management and financial well-being.

\section{Can FHI explain real-life financial behaviors?}

In the final sample of 2002 respondents that answered to the FHI scale and performed the behavioral finance tasks, we also collected information about general financial behavior using the Financial Management Behavioral Scale (Dew and Xiao 2011), ${ }^{10}$ as well as information about financial wellbeing using CFPB Financial Well-Being Scale (Consumer Financial Protection Bureau 2017). In addition, we asked subjects whether they have ever made an active choice on how to invest their Premium Pension Plan, whether they have ever taken an SMS loan (an instant short-term loan with high interest rates that can be applied for via SMS), and what is the financial situation of their household.

\footnotetext{
${ }^{10}$ We have narrowed down the FMBS scale to following subscales: savings and investment, cash management, and credit management. We have excluded the insurance subscale as we were not interested in insurance-related behavior. Furthermore, we have adjusted some of the items in the original FMBS scale to better fit Swedish respondents (e.g., credit card usage is relatively uncommon in Sweden).
} 
Each of these measures gives an insight into individuals' financial health and financial well-being. We reasoned that individuals scoring high on the FHI scale would manifest worse financial health, i.e., be relatively worse in managing their household finance, be more likely to take instant loans, be less likely to make active financial choices that affect their future financial situation, as well as have lower financial well-being. We do not have clear predictions when it comes to perceived financial situation. On one hand, individuals who score high on financial ignorance should on average have objectively worse financial situation (due to the ignorance of relevant decision aspects), however, as the proverb says "ignorance is a bliss" and thus individuals who are ignorant might perceive their situation to be better than it is.

We have conducted a series of linear regressions to explain each of the above-described outcome variables. We have used the FHI scale as explanatory variable. In the regression models we use the following control variables: age (in years), gender (binary variable that takes value 1 if female and 0 if male), education (four-category variable), the "big five" of financial literacy (can take values between 0 - low fin literacy and 5 - high fin literacy) (Lusardi and Mitchell 2008, Lusardi 2011), and household income (ten-category variable with equal intervals except for the first and last category, here treated as continuous variable).

Table 9 presents the results from linear regressions on the following outcome variables: financial management behavioral scale (FMBS), financial well-being, having taken an SMS loan, having made an active choice of pension fund investment, and self-reported household's financial situation. In the specification we have included a similar battery of control variables as in previous regressions: age, gender, education, financial literacy, adding household income. The results show that the FHI scale can explain each of the financial outcome variables. Individuals scoring higher on the FHI scale (i.e., showing higher financial ignorance) are worse at managing their finance, have lower financial wellbeing, are more likely to have taken an instant high-cost SMS loan, are less likely to make an active choice of how to invest their funds in Premium Pension Plan, and self-report worse financial situation of their household. In fact, FHI scale is the strongest predictor of financial management and of taking an SMS loan and a second strongest predictor of financial well-being and self-reported household financial situation (all standardized beta coefficients are listed in Table S3 in Appendix). Notably, the FHI scale is a strong predictor of all outcomes broadly related to financial health that are listed in Table 9. 
Table 9 Linear regressions explaining the financial management, financial well-being, having taken an instant high-cost SMS loan, active choice of pension investment, and self-reported financial situation.

\begin{tabular}{|c|c|c|c|c|c|}
\hline VARIABLES & FMBS & $\begin{array}{c}\text { Financial Well- } \\
\text { being }\end{array}$ & SMS loan & $\begin{array}{c}\text { Active Pension } \\
\text { Choice }\end{array}$ & $\begin{array}{l}\text { Financial } \\
\text { Situation } \\
\end{array}$ \\
\hline FHI & $\begin{array}{c}-0.370 * * * \\
(0.025)\end{array}$ & $\begin{array}{c}-1.031 * * * \\
(0.164)\end{array}$ & $\begin{array}{c}0.120 * * * \\
(0.014)\end{array}$ & $\begin{array}{c}-0.054 * * * \\
(0.017)\end{array}$ & $\begin{array}{c}-0.579 * * * \\
(0.042)\end{array}$ \\
\hline Age & $\begin{array}{c}-0.002 * * \\
(0.001)\end{array}$ & $\begin{array}{c}0.084 * * * \\
(0.006)\end{array}$ & $\begin{array}{c}-0.001 * * \\
(0.000)\end{array}$ & $\begin{array}{c}0.009 * * * \\
(0.001)\end{array}$ & $\begin{array}{c}0.001 \\
(0.001)\end{array}$ \\
\hline Female & $\begin{array}{c}0.020 \\
(0.029)\end{array}$ & $\begin{array}{l}-0.169 \\
(0.187)\end{array}$ & $\begin{array}{c}-0.025 * * \\
(0.012)\end{array}$ & $\begin{array}{c}0.017 \\
(0.020)\end{array}$ & $\begin{array}{l}-0.060 \\
(0.045)\end{array}$ \\
\hline Education, Upper-sec. & $\begin{array}{l}0.101^{*} \\
(0.053)\end{array}$ & $\begin{array}{l}-0.388 \\
(0.372)\end{array}$ & $\begin{array}{l}-0.004 \\
(0.022)\end{array}$ & $\begin{array}{c}0.119 * * * \\
(0.038)\end{array}$ & $\begin{array}{c}0.084 \\
(0.092)\end{array}$ \\
\hline $\begin{array}{l}\text { Education, Post-sec. } \\
\text { lower }\end{array}$ & $\begin{array}{c}0.173 * * * \\
(0.058)\end{array}$ & $\begin{array}{l}-0.571 \\
(0.399)\end{array}$ & $\begin{array}{l}-0.014 \\
(0.023)\end{array}$ & $\begin{array}{c}0.213 * * * \\
(0.040)\end{array}$ & $\begin{array}{c}0.080 \\
(0.098)\end{array}$ \\
\hline $\begin{array}{l}\text { Education, Post-sec. } \\
\text { higher }\end{array}$ & $\begin{array}{c}0.246 * * * \\
(0.054)\end{array}$ & $\begin{array}{c}0.078 \\
(0.377)\end{array}$ & $\begin{array}{l}-0.022 \\
(0.022)\end{array}$ & $\begin{array}{l}0.132 * * * \\
(0.039)\end{array}$ & $\begin{array}{c}0.121 \\
(0.092)\end{array}$ \\
\hline Fin. literacy & $\begin{array}{c}0.071 * * * \\
(0.011)\end{array}$ & $\begin{array}{l}-0.112 \\
(0.074)\end{array}$ & $\begin{array}{l}-0.004 \\
(0.005)\end{array}$ & $\begin{array}{c}0.064 * * * \\
(0.008)\end{array}$ & $\begin{array}{l}0.044 * * \\
(0.019)\end{array}$ \\
\hline Household Income & $\begin{array}{c}0.056 * * * \\
(0.006)\end{array}$ & $\begin{array}{c}0.227 * * * \\
(0.039)\end{array}$ & $\begin{array}{c}0.000 \\
(0.002)\end{array}$ & $\begin{array}{c}0.031 * * * \\
(0.004)\end{array}$ & $\begin{array}{c}0.155^{* * *} \\
(0.010)\end{array}$ \\
\hline Constant & $\begin{array}{c}3.722 * * * \\
(0.097)\end{array}$ & $\begin{array}{l}49.782 * * * \\
(0.672)\end{array}$ & $\begin{array}{c}-0.084 * * \\
(0.043)\end{array}$ & $\begin{array}{l}-0.130 * \\
(0.068)\end{array}$ & $\begin{array}{l}4.080 * * * \\
(0.170)\end{array}$ \\
\hline $\begin{array}{l}\text { Observations } \\
\text { R-squared }\end{array}$ & $\begin{array}{l}1,989 \\
0.235\end{array}$ & $\begin{array}{l}1,989 \\
0.178\end{array}$ & $\begin{array}{l}1,989 \\
0.109\end{array}$ & $\begin{array}{l}1,989 \\
0.243\end{array}$ & $\begin{array}{l}1,989 \\
0.259\end{array}$ \\
\hline
\end{tabular}

Note: Robust standard errors in parentheses. ${ }^{* *} \mathrm{p}<0.01,{ }^{* *} \mathrm{p}<0.05,{ }^{*} \mathrm{p}<0.1$. Dependent variable is listed at the top of each column. FMBS (Financial Management Behavioral Scale) takes values between 1 (poor financial management) and 5 (good financial management). Financial Well-being takes values between 1 (low financial well-being) and 100 (high financial wellbeing). SMS loan takes values 1 if a person has taken an SMS loan at least once and 0 otherwise. Active Pension Choice takes values 1 if a person has made an active choice how to invest Premium Pension Plan at least once and 0 otherwise. Financial Situation (self-reported) takes values between 1 (very bad) and 5 (very good). FHI takes values between 1 (low ignorance) and 5 (high ignorance). The reference category for education is lower-secondary. Financial Literacy takes values between 0 (low financial literacy) and 5 (high financial literacy). Household Income is measured in intervals of 10000 sek $(\sim \$ 1000)$. Number of observations is lower than 2002, due to missing observations of the household income.

\section{Discussion and conclusions}

In this study we unify previous research on financial ignorance within the financial domain and examine its role in financial decision-making and financial well-being. We suggest that people are sometimes what we call Financial Homo Ignorans (FHI), i.e., on occasions, they manifest tendencies to ignore relevant aspects of decision-making. We develop and validate the FHI scale to operationalize the concept of financial ignorance. Furthermore, we test how well it predicts financial behavior and outcomes related to financial health.

Our FHI scale involves self-report measures of three components of information ignorance: information avoidance (e.g., decision avoidance), information neglect (e.g., aggregation neglect), and information distortion (e.g., motivated reasoning) and thus our aggregate scale captures a broader range of psychological mechanisms than previous research (Ho et al. 2020). In addition, while previous research on information avoidance have examined other specific domains such as avoidance of health-related behaviors (Gigerenzer and Garcia-Retamero 2017), the FHI scale is the first scale that is focused on financial information neglect. 
We find that there is a large range of FHI scores in our sample suggesting that there are substantial individual differences. In terms of demographic characteristics, we find that younger individuals, with children, and men on average score higher on the FHI scale. It is possible that in general, young individuals care less about financial decisions as they have their "whole life" in front of them and postpone relevant financial decisions, such as retirement savings, for the future. An unexpected finding was that individuals with children are more ignorant about financial issues. Arguably, individuals with children are expected to care more about their financial situation and ensuring financial resources for the expenses of their children (e.g., after-school activities, education, etc.). A possible explanation for this finding is that people with children tend to experience both financial and non-financial stress (Friedline et al. 2020) which may crowd out deliberate attention to financial issues. Moreover, we find that men exhibit greater ignorance than women in the financial domain. This may stem from the fact that men of have a higher general confidence in their own skills, knowledge and capabilities to make good decisions (Lind et al. 2020).

But are individual differences in FHI related to relevant financial outcomes? Our results show that the scale performs well in predicting behavior related to financial tasks, such as choosing a loan, postponing investment decisions, or acquiring more information. It is also related to self-reported real-life financial behavior such as taking an instant SMS loan (usually with extremely high interest rate) or making an active choice about pension investments. Overall, higher scores on FHI are negatively associated with general financial management. Furthermore, the FHI scale has a direct and indirect (through financial management) impact on financial well-being. These findings clearly indicate that the FHI scale can be a valuable tool in intervention design as well as for welfare analysis.

The detailed picture of financial ignorance offered by the FHI scale is relevant for policy makers and financial institutions. First of all, the FHI scale can be used to determine areas in which behavioral interventions can be introduced to improve individuals' well-being. By identifying individual differences in financial behavior, policy makers will be able to customize financial policies to target most vulnerable individuals. Furthermore, the FHI scale can give insights into designing more effective interventions and policies to which even most ignorant individuals are responsive.

In addition, once aware of the problem of behavioral ignorance, financial institutions can tailor their services to help individuals make better financial choices. This can be done using simple behavioral measures and adjusting the choice architecture (Richard H Thaler and Sunstein 2008) or by boosting the individual capacity (Grüne-Yanoff and Hertwig 2016). When we know that individuals ignore specific information, we can make sure that it is more salient as well as readily available to them. In addition, the FHI scale can be used as a tool to identify individuals who might be at increased risk of financial problems. This in turn, allows financial institutions to target such individuals with behavioral interventions to prepare them to be more resilient in the times of financial hardship. At the same time, welfare analysis must consider the cost of information (Sharot and Sunstein 2020). If people avoid 
information because it makes them feel unpleasant, welfare analysis must weigh the hedonic costs of information against the behavioral gain. The FHI scale may thus directly help public agencies and institutions to assess what information people avoid and who avoids information to improve the quality of public policy.

We acknowledge that the FHI scale is not exhaustive and there might be other factors of the decisionmaking that individuals tend to ignore which also contribute to poor financial decisions. However, in its current form, FHI is a very short, concise and easy to administer scale that gives a comprehensive picture of financial ignorance. It is our hope that the FHI scale will be a step toward making data on financial ignorance more accessible to policymakers to inform policy design and evaluations as well as for other researchers to employ in their studies.

The FHI scale is a complementary measure to financial literacy in that both high financial literacy and lack of financial ignorance are precursors to sound financial decision making. However, we also show that the two concepts are different - decreasing ignorance can help improve decisions of individuals irrespective of their level of financial literacy. For instance, one can stop postponing decision to save for retirement regardless of whether she has the knowledge of financial terms. In other words, behavioral interventions targeting financial ignorance can lead to better financial decisions and thus improved financial well-being without necessarily targeting financial literacy. In addition, simply teaching individuals about how personal finance works might not be sufficient if participants in financial education programs do not internalise, but avoid, the information provided. 


\section{References}

Anderson CJ (2003) The psychology of doing nothing: Forms of decision avoidance result from reason and emotion. Psychological Bulletin 129(1):139-167.

Antonides G, Manon de Groot I, Fred van Raaij W (2011) Mental budgeting and the management of household finance. Journal of Economic Psychology 32(4):546-555.

Bandura A (2010) Self-Efficacy. The Corsini Encyclopedia of Psychology, 1-3.

Blackwell D (1953) Equivalent comparisons of experiments. The Annals of Mathematical Statistics 24:265-272.

Broniarczyk SM, Griffin JG (2014) Decision Difficulty in the Age of Consumer Empowerment. Journal of Consumer Psychology 24(4):608-625.

Carpenter S (2018) Ten Steps in Scale Development and Reporting: A Guide for Researchers. Communication Methods and Measures 12(1):25-44.

Comrey AL, Lee HB (2013) A first course in factor analysis (Psychology press).

Consumer Financial Protection Bureau (2017) Financial Well-Being Scale. Scale Development Technical Report. Report.

De Bondt WFM, Thaler RH (1995) Chapter 13 Financial decision-making in markets and firms: A behavioral perspective. Handbooks in Operations Research and Management Science, vol. 9 (Elsevier), 385-410.

Dew J, Xiao JJ (2011) The financial management behavior scale: Development and validation. Journal of Financial Counseling and Planning 22(1):43.

Dhar R (1997) Consumer Preference for a No-Choice Option. Journal of Consumer Research 24(2):215-231.

Frederick S, Novemsky N, Wang J, Dhar R, Nowlis S (2009) Opportunity Cost Neglect. Journal of Consumer Research 36(4):553-561.

Friedline T, Chen Z, Morrow SP (2020) Families' Financial Stress \& Well-Being: The Importance of the Economy and Economic Environments. Journal of Family and Economic Issues.

Ganguly A, Tasoff J (2017) Fantasy and Dread: The Demand for Information and the Consumption Utility of the Future. Management Science 63(12):4037-4060.

Gigerenzer G, Garcia-Retamero R (2017) Cassandra's regret: The psychology of not wanting to know. Psychological review 124(2):179-196.

Golman R, Hagmann D, Loewenstein G (2017) Information avoidance. Journal of Economic Literature 55(1):96-135.

Grüne-Yanoff T, Hertwig R (2016) Nudge Versus Boost: How Coherent are Policy and Theory? Minds and Machines 26(1):149-183.

Heath C, Soll JB (1996) Mental Budgeting and Consumer Decisions. Journal of Consumer Research 23(1):40-52. 
Hertwig R, Engel C (2016) Homo Ignorans: Deliberately Choosing Not to Know. Perspectives on Psychological Science 11(3):359-372.

Ho EH, Hagmann D, Loewenstein G (2020) Measuring Information Preferences. Management Science. Howell JL, Shepperd JA (2016) Establishing an Information Avoidance Scale. Psychological assessment 28(12):1695.

Karlsson N, Loewenstein G, Seppi D (2009) The ostrich effect: Selective attention to information. Journal of Risk and uncertainty 38(2):95-115.

Lind T, Erlandsson A, Västfjäll D, Tinghög G (2018) Motivated reasoning when assessing the effects of refugee intake. Behavioural Public Policy:1-24.

Lind T, Ahmed A, Skagerlund K, Strömbäck C, Västfjäll D, Tinghög G (2020) Competence, Confidence, and Gender: The Role of Objective and Subjective Financial Knowledge in Household Finance. Journal of Family and Economic Issues.

Lown JM (2011) Development and validation of a financial self-efficacy scale. Journal of Financial Counseling and Planning 22(2):54.

Luce MF (1998) Choosing to Avoid: Coping with Negatively Emotion-Laden Consumer Decisions. Journal of Consumer Research 24(4):409-433.

Lunn P, Bohacek M, Rybicki A (2016) An Experimental Investigation of Personal Loan Choices. Economic and Social Research Institute (ESRI).

Lusardi A (2011) Americans' Financial Capability. National Bureau of Economic Research Working Paper Series No. 17103.

Lusardi A, Mitchell OS (2008) Planning and Financial Literacy: How Do Women Fare? American Economic Review 98(2):413-17.

Lynch Jr JG, Netemeyer RG, Spiller SA, Zammit A (2010) A generalizable scale of propensity to plan: The long and the short of planning for time and for money. Journal of Consumer Research 37(1):108128.

Minson JA, Chen FS, Tinsley CH (2019) Why Won't You Listen to Me? Measuring Receptiveness to Opposing Views. Management Science 66(7):3069-3094.

Reisch L, Sunstein C, Kaiser M (2020) What Do People Want to Know? An International Survey. SSRN Electronic Journal.

Sharot T, Sunstein CR (2020) How people decide what they want to know. Nature Human Behaviour 4(1):14-19.

Simon HA (1955) A Behavioral Model of Rational Choice. The Quarterly Journal of Economics 69(1):99-118.

Skagerlund K, Lind T, Strömbäck C, Tinghög G, Västfjäll D (2018) Financial literacy and the role of numeracy-How individuals' attitude and affinity with numbers influence financial literacy. Journal of Behavioral and Experimental Economics 74:18-25.

Spiller SA (2011) Opportunity Cost Consideration. Journal of Consumer Research 38(4):595-610. 
Strömbäck C, Skagerlund K, Västfjäll D, Tinghög G (2020) Subjective self-control but not objective measures of executive functions predicts financial behavior and well-being. Journal of Behavioral and Experimental Finance:100339.

Strömbäck C, Lind T, Skagerlund K, Västfjäll D, Tinghög G (2017) Does self-control predict financial behavior and financial well-being? Journal of Behavioral and Experimental Finance 14:30-38 Article. Sunstein CR (2006) Boundedly Rational Borrowing. The University of Chicago Law Review 73(1):249270.

--- (2020) Too Much Information: Understanding What You Don't Want to Know (MIT Press).

Sweeny K, Melnyk D, Miller W, Shepperd JA (2010) Information Avoidance: Who, What, When, and Why. Review of General Psychology 14(4):340-353.

Thaler RH (1999) Mental accounting matters. Journal of Behavioral Decision Making 12(3):183-206. Thaler RH, Sunstein CR (2008) Nudge: Improving decisions about health, wealth, and happiness (Yale University Press).

Weinstein ND (1980) Unrealistic optimism about future life events. Journal of Personality and Social Psychology 39(5):806-820.

Worthington RL, Whittaker TA (2006) Scale Development Research: A Content Analysis and Recommendations for Best Practices. The Counseling Psychologist 34(6):806-838. 